\title{
MENINGKATKAN KEMAMPUAN PEMECAHAN MASALAH DAN HASIL BELAJAR MELALUI MODEL PEMBELAJARAN PROBLEM SOLVING MATERI REAKSI REDUKSI DAN OKSIDASI
}

\author{
Improving Problem Solving Ability and Learning Outcomes through \\ Problem Solving Learning Model on Reaction and Oxidation Material
}

Rizki Ramadana Putri*, Bambang Suharto, Muhammad Kusasi Program Studi Pendidikan Kimia FKIP Universitas Lambung Mangkurat, Jl. Brigjend. H. Hasan Basry Banjarmasin 70123 Kalimantan Selatan Indonesia *email: $1610120220015 @$ mhs.ulm.ac.id

\begin{abstract}
Abstrak. Telah dilakukan penelitian guna meningkatkan (1) hasil belajar (a) pengetahuan, (b) sikap, (c) keterampilan, dan (2) kemampuan pemecahan masalah melalui model problem solving pada materi reaksi redoks. Penelitian dilakukan di kelas X MIPA 5 SMAN 2 Banjarmasin. Hasil penelitian menunjukkan: (1) hasil belajar (a) pengetahuan meningkat sebesar 32,41\%, (b) sikap meningkat sebesar $54,84 \%$, (c) keterampilan meningkat sebesar 51,61\%, dan (2) kemampuan pemecahan masalah meningkat sebesar 47,43\%.
\end{abstract}

Kata kunci: hasil belajar, kemampuan pemecahan masalah

\begin{abstract}
Classroom Action Research (CAR) had been done to improve (1) learning outcomes (a) knowledge, (b) attitude, (c) skill, and (2) problem solving ability through problem solving model on redox reaction material. The research had been conducted in class X MIPA 5 SMAN 2 Banjarmasin. The results show that: (1) learning outcomes (a) knowledge increased by $32.41 \%$, (b) attitude increased by $54.84 \%$, (c) skill increased by $51.61 \%$, and (2) problem solving ability increased by $47.43 \%$.
\end{abstract}

Keywords: learning outcomes, problem solving ability

\section{PENDAHULUAN}

Materi pembelajaran kimia terutama materi reaksi redoks masih dianggap sukar dipelajari peserta didik kelas X MIPA 5 SMAN 2 Banjarmasin. Kesukaran peserta didik disebabkan materi ini memiliki karakteristik faktual, konseptual, dan prosedural yang berkaitan. Data hasil belajar menunjukkan sebanyak $55,56 \%$ peserta didik tidak tuntas $(\mathrm{KKM}=75)$. Pengerjaan latihan soal yang intensif telah diberikan pendidik untuk memperbaiki kemampuan pemecahan masalah. Namun, hasilnya masih jauh dari yang diharapkan. Hal ini diakibatkan pendidik melaksanakan model DI (Direct Instruction) yang berpusat pada pendidik, sedangkan praktikum dan diskusi kelompok hampir tidak pernah dilaksanakan. Model problem solving yang berlandaskan teori belajar konstruktivisme diyakini dapat mengatasi permasalahan tersebut.

Menurut Ulya, Rudibyani, dan Efkar (2018), hasil belajar dan kemampuan memecahkan masalah peserta didik dapat ditingkatkan melalui pelaksanaan model problem solving. Kemampuan mengolah informasi dari sumber belajar secara mandiri dan konstruksi pengetahuan lama dengan pengetahuan baru yang didapatkan peserta didik dalam pelaksanaannya diyakini sebagai faktor peningkatan tersebut. Berdasarkan uraian di atas, maka peneliti melakukan penelitian untuk meningkatkan kemampuan pemecahan masalah dan hasil belajar melalui model pembelajaran

Copyright @ JCAE-Jurnal Tugas Akhir Mahasiswa, e-ISSN 2613-9782

Program Studi Pendidikan Kimia FKIP Universitas Lambung Mangkurat 
problem solving pada materi reaksi reduksi dan oksidasi peserta didik kelas X MIPA 5 SMA Negeri 2 Banjarmasin

\section{METODE PENELITIAN}

Penelitian Tindakan Kelas (PTK) dilaksanakan dalam 2 siklus, dimana pada siklus I pertemuan I dilaksanakan kegiatan pembelajaran dan praktikum, sedangkan pertemuan II dilaksanakan evaluasi, demikian pula pada siklus II. Penelitian dilakukan untuk meningkatkan hasil belajar dan kemampuan pemecahan masalah dari 35 orang peserta didik kelas X MIPA 5 SMAN 2 Banjarmasin. Adapun desain PTK model Kemmis, McTaggart, dan Nixon (2014) dapat dilihat pada gambar 1.

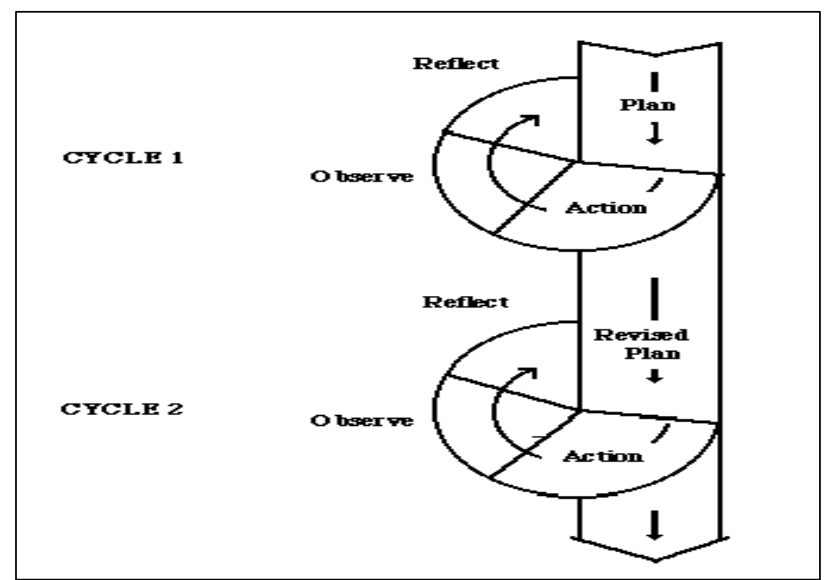

Gambar 1. Model PTK

\section{HASIL PENELITIAN DAN PEMBAHASAN}

\section{Hasil Belajar Pengetahuan}

Hasil belajar pengetahuan peserta didik dapat dilihat pada gambar 2 .

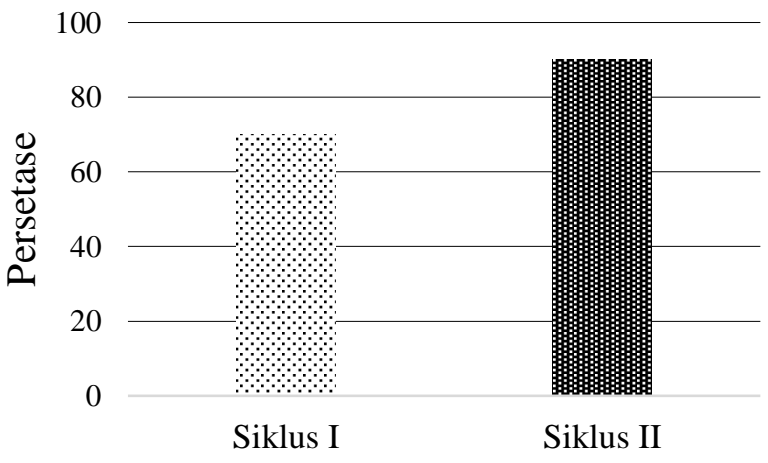

Gambar 2. Hasil belajar pengetahuan

Hasil belajar pengetahuan meningkat dari $68,81 \%$ menjadi $91,11 \%$. Peningkatan terjadi karena pendidik memberikan pembahasan dan pengulangan materi pembelajaran. Menurut Winarti dan Suharto (2017), hal ini diperlukan agar peserta didik dapat mengerjakan soal latihan dengan maksimal.

Peningkatan juga terjadi karena pendidik memberikan soal berbasis masalah. Kharisma, Susilowati, dan Ridlo (2018) menyatakan pembelajaran berorientasi 
pemecahan masalah berdampak positif terhadap hasil belajar pengetahuan. Selain itu, menurut Hartini, Kusasi, dan Iriani (2017), pengetahuan yang dibangun dalam konteks pemecahan masalah dapat meningkatkan hasil belajar pengetahuan.

Selanjutnya, peningkatan terjadi karena model problem solving yang berpusat pada peserta didik dilaksanakan untuk mengonstruksi pengetahuan. Menurut Zulfah dan Senam (2018), model ini dapat mengonstruksi pengetahuan, sedangkan Ariyanto, Kristin, dan Anugraheni (2018) menyatakan model ini dapat meningkatkan hasil belajar pengetahuan. Selain itu, menurut Novianti, Rusmansyah, dan Kusasi (2017), kegiatan pembelajaran yang berpusat pada peserta didik membangun pengetahuan, sikap, perilaku, dan meningkatkan hasil belajar pengetahuan.

\section{Hasil Belajar Sikap}

Hasil belajar sikap peserta didik dapat dilihat pada gambar 3.

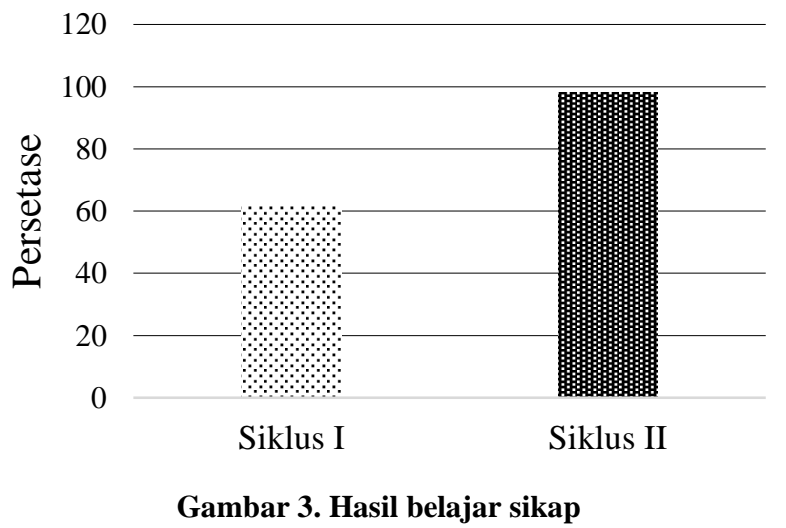

Hasil belajar sikap meningkat dari $62 \%$ menjadi $96 \%$. Peningkatan rasa ingin tahu terjadi karena pendidik memusatkan perhatian peserta didik sebelum memberikan penjelasan dan arahan. Menurut Vogler, Prediger, Quasthoff, dan Heller (2018), pemusatan perhatian dapat meningkatkan rasa ingin tahu. Peserta didik juga diberi kesempatan tanya jawab dan mengutarakan pendapat. Menurut Singaravelu (2017), kegiatan ini berdampak positif terhadap rasa ingin tahu.

Pendidik memberikan umpan balik berupa penguatan dan penghargaan kepada peserta didik yang aktif. Menurut Agricola, Prins, dan Sluijsmans (2020), umpan balik berdampak positif terhadap rasa ingin tahu. Selain itu, menurut Bashir, Kabir, dan Rahman (2016), pemberian umpan balik memungkinkan identifikasi kebenaran pengetahuan yang dimiliki. Selama memecahkan masalah, peserta didik mengumpulkan informasi dari sumber belajar yang relevan dan tepercaya. Menurut Santi, Suharto, dan Leny (2019), penggunaan sumber belajar berdampak positif terhadap rasa ingin tahu.

Adapun peningkatan kerja sama terjadi karena peserta didik berdiskusi kelompok dengan maksimal. Menurut Arif, Istiadji, dan Syahmani (2018), diskusi kelompok membuat peserta didik lebih mudah bekerja sama. Selain itu, menurut Amanda, Suharto, dan Mahdian (2017), diskusi kelompok memudahkan memahami materi pembelajaran dan meningkatkan kerja sama. Peserta didik juga bertukar pikiran dan memberikan saran, kritik, atau tanggapan kepada peserta didik lainnya. Menurut Nurdyansah, Masitoh, dan Bachri (2018), kerja sama dapat ditingkatkan melalui kegiatan bertukar pikiran antar peserta didik. 
Hasil Belajar Keterampilan

Hasil belajar keterampilan peserta didik dapat dilihat pada gambar 4.

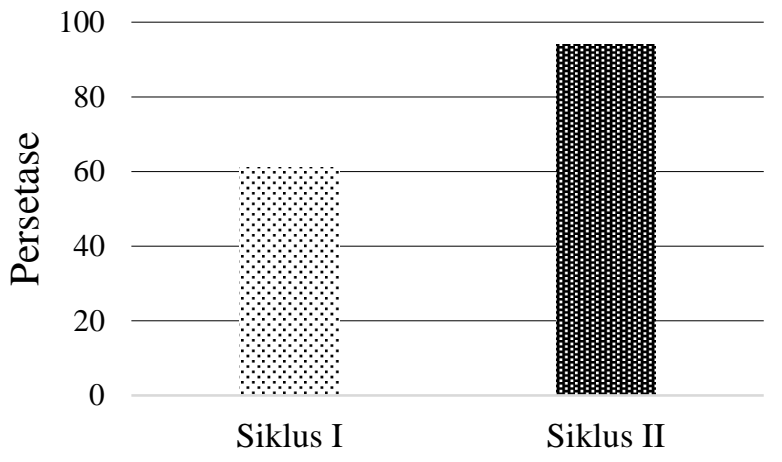

Gambar 4. Hasil belajar keterampilan

Hasil belajar keterampilan meningkat dari $62 \%$ menjadi $94 \%$. Peningkatan terjadi karena peserta didik melakukan praktikum dengan terampil. Peserta didik menggunakan pipet tetes dengan benar dimana ibu jari dan telunjuk menekan karet pipet tetes dan jari-jari yang lain memegang bagian gelas pipet tetes agar larutan masuk ke dalam wadah secara sempurna. Peserta didik juga menggunakan pipet tetes untuk mengambil satu jenis larutan sehingga tidak tercampur. Selain itu, peserta didik juga menggunakan gelas ukur dengan memerhatikan batas meniskus dan meletakkan pada bidang yang rata saat mengukur volume larutan.

Peningkatan juga terjadi karena pendidik membimbing peserta didik menggunakan alat dan bahan praktikum dengan maksimal. Menurut Nursidah, Suharto, dan Rusmansyah (2019), bimbingan diperlukan agar memeroleh pengalaman langsung dan menghindari kesalahan selama praktikum. Selain itu, menurut Putri, Suharto, dan Rusmansyah (2019), praktikum dapat melatih keterampilan.

\section{Kemampuan Pemecahan Masalah}

Kemampuan pemecahan masalah peserta didik dapat dilihat pada gambar 5 .

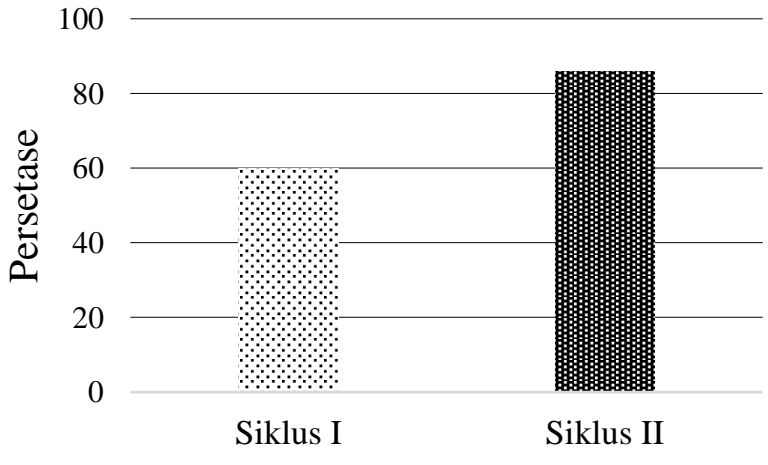

Gambar 5. Kemampuan pemecahan masalah

Kemampuan pemecahan masalah meningkat dari 60,45\% menjadi $89,12 \%$. Peningkatan terjadi karena pendidik memberikan permasalahan rutin atau non rutin. 
Menurut Simamora, Saragih, dan Hasratuddin (2019), pemberian permasalahan rutin atau non rutin berdampak positif terhadap peningkatan kemampuan pemecahan masalah. Selain itu, peserta didik melaksanakan model problem solving. Menurut Iqbal, Rudibyani, dan Efkar (2018), model ini dapat meningkatkan kemampuan pemecahan masalah.

Peserta didik memahami masalah dengan menuliskan permasalahan dan seluruh data dengan lengkap. Selanjutnya, peserta didik menentukan strategi pemecahan masalah dengan mengonstruksi pengetahuan lama dengan pengetahuan baru serta mengumpulkan informasi dari sumber belajar. Menurut Aryanti dan Kusasi (2016), konstruksi pengetahuan diperlukan saat merencanakan strategi pemecahan masalah. Selain itu, menurut Dasrita (2018), peserta didik perlu mengumpulkan informasi dari sumber belajar untuk merencanakan strategi pemecahan masalah.

Peserta didik memecahkan masalah sesuai strategi yang direncanakan. Menurut Saygili (2017), pemecahan masalah dilakukan melalui pengumpulan informasi dari sumber belajar dan menghubungkan dengan strategi pemecahan masalah. Selanjutnya, peserta didik memeriksa kembali pemecahan masalah. Menurut Hasan (2019), hal ini dilakukan melalui evaluasi langkah-langkah pemecahan masalah sehingga didapatkan kesimpulan.

\section{SIMPULAN}

Pelaksanaan model problem solving pada materi reaksi redoks meningkatkan (1) hasil belajar (a) pengetahuan sebesar 32,41\%, (b) sikap sebesar 54,84\%, (c) keterampilan sebesar $51,61 \%$, dan (2) kemampuan pemecahan masalah sebesar $47,43 \%$.

\section{DAFTAR RUJUKAN}

Agricola, B. T., Prins, F. J., \& Sluijsmans, M. A. (2020). Impact of Feedback Request Forms and Verbal Feedback on Higher Education Students' Feedback Perception, Self-Efficacy, and Motivation. Assessment in Education: Principles, Policy, and Practice, 27(1), 6-25.

Amanda, R. R., Suharto, B., \& Mahdian. (2017). Meningkatkan Aktivitas dan Hasil Belajar Siswa dengan Model Pembelajaran Inkuiri Terbimbing pada Materi Redoks. QUANTUM Jurnal Inovasi Pendidikan Sains, 8(1), 43-51.

Arif, Istiadji, M., \& Syahmani. (2018). Implementasi Problem Based Learning Berbantuan Diskusi Daring terhadap Kemampuan Pemecahan Masalah dan Hasil Belajar Kimia pada Materi Larutan Penyangga. Journal of Chemistry and Education, 1(3), 237-244.

Ariyanto, M., Kristin, F., \& Anugraheni, I. (2018). Penerapan Model Pembelajaran Problem Solving untuk Meningkatkan Kemampuan Berpikir Kritis dan Hasil Belajar Siswa. Jurnal Guru Kita, 2(3), 106-115.

Aryanti, R. \& Kusasi, M. (2016). Pembelajaran Kimia Berbasis Problem Solving Menggunakan Laboratorium Riil dan Virtual Ditinjau dari Gaya Belajar dan Hasil Belajar pada Materi Larutan Elektrolit dan Nonelektrolit. QUANTUM Jurnal Inovasi Pendidikan Sains, 7(2), 135-138.

Bashir, M. A., Kabir, R., \& Rahman, I. (2016). The Value and Effectiveness of Feedback in Improving Students' Learning and Professionalizing Teaching in Higher Education. Journal of Education and Practice, 7(16), 38-41.

Dasrita, Y. (2018). Meningkatkan Hasil Belajar Kimia Siswa Kelas XI SMA Negeri 1 Bangkinang Melalui Metode Pembelajaran Problem Solving. Jurnal Pendidikan Tambusai, 2(5), 1116-1126.

Hartini, E. M., Kusasi, M., \& Iriani, R. (2017). Meningkatkan Keterampilan Proses 
Sains dan Hasil Belajar Melalui Model Problem Solving dengan Pendekatan Saintifik pada Materi Hidrolisis Garam. Journal of Chemistry and Education, $1(1), 37-45$.

Hasan, B. (2019). The Analysis of Students' Critical Thinking Ability with Visualizer-Verbalizer Cognitive Style. International Journal of Trends Education Research, 2(3), 142-147.

Iqbal, M., Rudibyani, R. B., \& Efkar, T. (2018). Penerapan Model Problem Solving dalam Meningkatkan Penguasaan Konsep Materi Asam Basa Arrhenius. Jurnal Pendidikan dan Pembelajaran Kimia, 7(1), 50-62.

Kemmis, S., McTaggart, R., \& Nixon, R. (2014). The Action Research Planner. Victoria: Springer.

Kharisma, F. N., Susilowati, S. M. E., \& Ridlo, S. (2018). Problem Solving Ability in Four Models of Learning. Journal of Innovative Science Education, 7(2), 229236.

Novianti, D., Rusmansyah, \& Kusasi, M. (2017). Meningkatkan Aktivitas dan Hasil Belajar Siswa Melalui Model Pembelajaran Problem Posing pada Materi Larutan Penyangga. Journal of Chemistry and Education, 1(1), 15-27.

Nurdyansah, S., Masitoh, \& Bachri, B. S. (2018). Problem Solving Model with Integration Pattern: Student's Problem Solving Capability. Advances in Social Science, Education, and Humanities Research, 173, 258-261.

Nursidah, Suharto, B., \& Rusmansyah. (2019). Penerapan Model Guided Discovery Learning untuk Meningkatkan Keterampilan Berpikir Kritis dan Hasil Belajar. Jurnal Vidya Karya, 34(1), 26-38.

Putri, F. R., Suharto, B., \& Rusmansyah. (2019). Penerapan Model Pembelajaran Inkuiri Terbimbing terhadap Hasil Belajar Peserta Didik pada Materi Koloid. Journal of Chemistry and Education, 3(2), 47-54.

Santi, Suharto, B., \& Leny. (2019). Model Project Based Learning Berbantuan Media Chemondro, Motivasi, dan Hasil Belajar. Jurnal Vidya Karya, 34(2), 122-131.

Saygili, S. (2017). Examining the Problem Solving Skills and the Strategies Used by High School Students in Solving Non Routine Problems. E-International Journal Education Research, 8(2), 91-114.

Simamora, R. E., Saragih, S., \& Hasratuddin. (2019). Improving Students' Problem Solving Ability and Self-Efficacy through Guided Discovery Learning in Local Culture Context. International Electronic Journal of Education, 14(1), 51-72.

Singaravelu, S. (2017). Problem Solving Ability of Higher Secondary Chemistry Students. IOSR Journal of Research and Method in Education, 7(4), 19-22.

Ulya, H., Rudibyani, R. B., \& Efkar, T. (2018). Pengembangan Modul Kimia Berbasis Problem Solving pada Materi Asam Basa Arrhenius. Jurnal Pendidikan dan Pembelajaran Kimia, 7(1), 129-141.

Vogler, A. M., Prediger, S., Quasthoff, U., \& Heller, V. (2018). Students' and Teachers' Focus of Attention in Classroom Interaction Subtle Sources for the Reproduction of Social Disparities. Education Research Journal, 30, 299-323.

Winarti, E. \& Suharto, B. (2017). Meningkatkan Motivasi dan Hasil Belajar Melalui Model Pembelajaran Auditory, Intellectually, Repetition pada Materi Larutan Penyangga di Kelas XI IPA SMA Muhammadiyah 1 Banjarmasin. Journal of Chemistry and Education, 1(1), 28-36.

Zulfah \& Senam. (2018). Problem Solving Ability of Students with Disciplinary Literacy Instruction. International Journal of Cognitive Research in Science, Engineering, and Education, 6(2), 81-88. 